Article

\title{
Hydrogenation of Levulinic Acid over Nickel Catalysts Supported on Aluminum Oxide to Prepare $\gamma$-Valerolactone
}

\author{
Jie Fu, Dong Sheng and Xiuyang $\mathrm{Lu}$ * \\ Received: 19 October 2015; Accepted: 23 December 2015; Published: 30 December 2015 \\ Academic Editor: Rafael Luque \\ Key Laboratory of Biomass Chemical Engineering of Ministry of Education, \\ College of Chemical and Biological Engineering, Zhejiang University, Hangzhou 310027, China; \\ jiefu@zju.edu.cn (J.F.); shengdong1990@163.com (D.S.) \\ * Correspondence: luxiuyang@zju.edu.cn; Tel./Fax: +86-571-8795-2683
}

\begin{abstract}
Four types of nickel catalysts supported on aluminum oxide $\left(\mathrm{Ni} / \mathrm{Al}_{2} \mathrm{O}_{3}\right)$ with different nickel loadings were synthesized using the co-precipitation method and were used for the hydrogenation of levulinic acid (LA) to prepare $\gamma$-valerolactone (GVL). The synthesized $\mathrm{Ni} / \mathrm{Al}_{2} \mathrm{O}_{3}$ catalysts exhibited excellent catalytic activity in dioxane, and the activity of the catalysts was excellent even after being used four times in dioxane. The catalytic activity in dioxane as a solvent was found to be superior to the activity in water. Nitrogen physisorption, $\mathrm{X}$-ray diffraction, and transmission electron microscopy were employed to characterize the fresh and used catalysts. The effects of the nickel loading, temperature, hydrogen pressure, and substrate/catalyst ratio on the catalytic activity were investigated.
\end{abstract}

Keywords: nickel supported on aluminum oxide; $\gamma$-valerolactone; levulinic acid; hydrogenation; dioxane

\section{Introduction}

Due to decreasing fossil reserves and the increasing demand for chemicals and fuels as a result of economic development, considerable attention has been focused on the utilization of renewable resources [1,2]. Biomass is a promising raw material for satisfying societal requirements for chemicals and fuels because it is abundant, inexpensive, and renewable [3]. Cellulose, an important biomass feedstock, has been investigated for producing many platform chemicals, such as 5-hydroxymethylfurfural (HMF) [4], levulinic acid (LA) [5], and $\gamma$-valerolactone (GVL) [6]. The GVL produced from this process can be used as a solvent, as a food additive, or as a key intermediate for producing other value-added chemicals [7]. The importance of GVL has recently increased because it has been used as a bridge between biomass and liquid fuels [8,9].

$\gamma$-Valerolactone can be synthesized through the hydrogenation of LA, another renewable platform chemical produced from biomass. It is a typical procedure for hydrogenation of carboxylic acids, whereby some heterogeneous catalysts are successfully applied for the hydrogenation of a carboxylic acid to the corresponding product [10]. The first step in producing GVL is hydrogenation of LA to form an intermediate, followed by an intramolecular cyclization reaction. At present, high temperatures, organic solvents, additives, complex separation procedures, and managing relatively high hydrogen pressures are often required for efficiently producing GVL, which together entail substantial energy inputs and the generation of large amounts of waste [11]. Many noble metal catalysts, such as Ru, Ir, $\mathrm{Rh}$, and $\mathrm{Pt}$, have been investigated for the hydrogenation of LA [12-18]. Luo et al. [19] reported that metal nano-alloys exert beneficial effects on the catalytic hydrogenation of LA to GVL. Although some noble metal catalysts exhibit excellent catalytic activity, the high price of noble metals hinders their 
application in industry. Copper-based catalysts, such as $\mathrm{Cu} / \mathrm{ZrO}_{2}$ [20,21], $\mathrm{Cu} / \mathrm{SiO}_{2}$ [22], $\mathrm{Cu}-\mathrm{Cr}$ [23], and $\mathrm{Cu}$-Fe [24], have been reported to be effective for producing GVL from LA, although a high temperature or long reaction time was required to achieve a high conversion of LA. Moreover, the reusability of these catalysts in such reactions has not received much attention.

Nickel-based catalysts, which are another choice of non-noble metal catalysts, may provide potential for easy recycling due to the strong magnetic properties of nickel-based catalysts. Recently, Ni/ $\mathrm{Al}_{2} \mathrm{O}_{3}$ and $\mathrm{Ni}-\mathrm{Cu} / \mathrm{Al}_{2} \mathrm{O}_{3}$ were prepared for the hydrogenation of LA using wet impregnation and sol-gel methods. The high reaction temperature $\left(250^{\circ} \mathrm{C}\right)$ and hydrogen pressure (6.5 MPa), however, limit the industrial applications of these catalysts [25]. Shimizu et al. [26] reported that $\mathrm{Ni}-\mathrm{MoO}_{x} / \mathrm{C}$ is the first noble metal-free catalyst with a TON of 4950 , which is comparable to the state-of-the-art Ru catalyst for the hydrogenation of LA to GVL at $250{ }^{\circ} \mathrm{C}$. Grunwaldt et al. [27] reported a solvent-free method that obtained a 92\% GVL yield for the synthesis of $\gamma$-valerolactone via the hydrogenation of $\mathrm{LA}$ over $\mathrm{Ni} / \mathrm{Al}_{2} \mathrm{O}_{3}$; however, reuse of the $\mathrm{Ni}$ catalysts resulted in a significant decrease in activity. Kamaraju Seetha Rama Rao et al. [28] demonstrated that $\mathrm{Ni} / \mathrm{SiO}_{2}$ prepared using the wet impregnation method provided a GVL yield of approximately $90 \%$ at $250{ }^{\circ} \mathrm{C}$, and $\mathrm{Ni} / \mathrm{SiO}_{2}$ retained almost the same activity after $25 \mathrm{~h}$. Rong et al. [29] reported that the highest selectivity $(93.3 \%)$ and productivity $\left(0.32 \mathrm{~mol}_{\mathrm{GVL}} \cdot \mathrm{g}_{\mathrm{metal}}{ }^{-1} \cdot \mathrm{h}^{-1}\right)$ of GVL were obtained under conditions of $150{ }^{\circ} \mathrm{C}$ and $1.0 \mathrm{MPa}$ for $2 \mathrm{~h}$. However, the activity of this catalyst could not be well maintained after recycling. In addition, the use of water as a solvent led to catalytic activity loss.

Palkovits [15] demonstrated that the choice of solvent has a strong influence on the hydrogenation catalytic system. Dioxane, a green and inexpensive solvent, was used in this study and could facilitate the reaction. Four nickel catalysts supported on aluminum oxide $\left(\mathrm{Ni} / \mathrm{Al}_{2} \mathrm{O}_{3}\right)$ with different nickel loadings were prepared using the co-precipitation method and were evaluated for the hydrogenation of LA to produce GVL in dioxane and water. Nitrogen physisorption, X-ray diffraction, transmission electron microscopy, and thermogravimetric analysis were used to characterize the fresh and used catalysts. The effects of temperature, hydrogen pressure, and substrate/catalyst ratio on the catalytic activity were also investigated.

\section{Results and Discussion}

\subsection{Catalyst Characterization}

Prior to characterization, the catalysts were reduced using hydrogen in a tube furnace (flow rate of $100 \mathrm{~mL} / \mathrm{min}$ ) at $650{ }^{\circ} \mathrm{C}$ for $3 \mathrm{~h}$.

Nickel-based catalysts, with various nickel loadings from $10 \%$ to $40 \%$, were prepared using the co-precipitation method. The $\mathrm{N}_{2}$ physisorption results of the prepared catalysts are presented in Table 1 . The $10 \% \mathrm{Ni} / \mathrm{Al}_{2} \mathrm{O}_{3}$ catalyst had the largest surface area $\left(181.3 \mathrm{~m}^{2} / \mathrm{g}\right)$, pore volume $\left(0.483 \mathrm{~cm}^{3} / \mathrm{g}\right)$, and pore size $(9.8 \mathrm{~nm})$. As the nickel loading increased, the surface area of the corresponding catalyst decreased from 168.8 to $133.7 \mathrm{~m}^{2} / \mathrm{g}$. Moreover, the pore volume of the catalyst decreased with increasing nickel loading. The pore size of the catalyst also decreased as the nickel loading increased, except for the $30 \% \mathrm{Ni} / \mathrm{Al}_{2} \mathrm{O}_{3}$ catalyst. These results indicate that the loaded nickel particles occupied a certain amount of the surface area and pore volume.

$X$-ray diffraction measurements were performed to determine the crystal phases in the structure of the catalysts and to calculate the average crystalline sizes. The XRD patterns of the catalysts are presented in Figure 1. Diffraction peaks assigned to metallic Ni were observed at $2 \theta$ angles of $44.3^{\circ}$, $51.7^{\circ}$, and $76.3^{\circ}$. As the nickel loading in the catalyst increased, the intensity of the diffraction peaks corresponding to metallic $\mathrm{Ni}$ increased. Mild diffraction peaks corresponding to the $\mathrm{NiAl}_{2} \mathrm{O}_{4}$ phase were also observed at angles of $37.5^{\circ}, 45.7^{\circ}$, and $67.0^{\circ}$. As shown in Table 1 , the average crystalline size of metallic $\mathrm{Ni}$ also increased with increasing nickel loading. Notably, the average crystalline size of metallic $\mathrm{Ni}$ in the $20 \% \mathrm{Ni} / \mathrm{Al}_{2} \mathrm{O}_{3}$ catalyst was found to be considerably larger than that in the $10 \%$ $\mathrm{Ni} / \mathrm{Al}_{2} \mathrm{O}_{3}$ catalyst. 
Table 1. Nitrogen physisorption and X-ray diffraction results of the catalysts.

\begin{tabular}{ccccc}
\hline Catalyst & $\begin{array}{c}\text { BET Surface } \\
\text { Area }\left(\mathbf{m}^{2} / \mathbf{g}\right)\end{array}$ & $\begin{array}{c}\text { Pore Volume } \\
\left(\mathbf{c m}^{\mathbf{3}} / \mathbf{g}\right)\end{array}$ & Pore Size $^{\mathbf{b}} \mathbf{( \mathbf { n m } )}$ & $\begin{array}{c}\text { Average Crystalline Size } \\
\text { of Metallic Ni }^{\mathbf{c}} \mathbf{( \mathbf { n m } )}\end{array}$ \\
\hline $10 \% \mathrm{Ni} / \mathrm{Al}_{2} \mathrm{O}_{3}$ & 181.3 & 0.483 & 9.80 & 8 \\
$20 \% \mathrm{Ni} / \mathrm{Al}_{2} \mathrm{O}_{3}$ & 168.8 & 0.426 & 8.52 & 14.7 \\
$30 \% \mathrm{Ni} / \mathrm{Al}_{2} \mathrm{O}_{3}$ & 145.7 & 0.377 & 8.86 & 17.7 \\
$40 \% \mathrm{Ni} / \mathrm{Al}_{2} \mathrm{O}_{3}$ & 133.7 & 0.327 & 8.32 & 19.3 \\
$40 \% \mathrm{Ni} / \mathrm{Al}_{2} \mathrm{O}_{3}$ & 133.1 & 0.275 & 7.50 & 19.1 \\
(used 4 times) & & & & \\
\hline
\end{tabular}

${ }^{\mathrm{a}} \mathrm{BJH}$ adsorption cumulative volume of pores between $1.70 \mathrm{~nm}$ and $300.00 \mathrm{~nm}$ in diameter; ${ }^{\mathrm{b}} \mathrm{BJH}$ adsorption average pore diameter $(4 \mathrm{~V} / \mathrm{A}){ }^{\mathrm{c}}$ Average crystalline sizes determined by X-ray line broadening analysis (XLBA) using the diffraction peak at $2 \theta=44.3^{\circ}$ for metallic Ni.

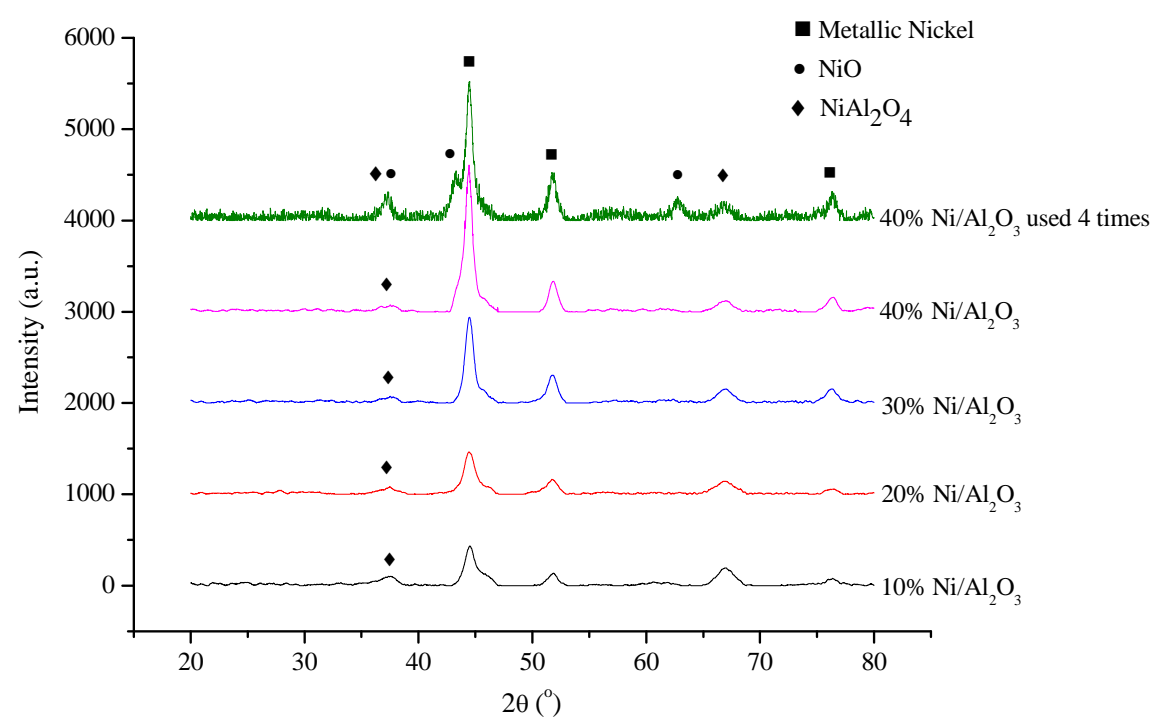

Figure 1. X-ray diffraction (XRD) patterns of $\mathrm{Ni} / \mathrm{Al}_{2} \mathrm{O}_{3}$ with different nickel loadings (JCPDS Cards: Metallic nickel: PDF65-0243; NiO: PDF22-1189; and $\mathrm{NiAl}_{2} \mathrm{O}_{4}$ : PDF01-1299).

Transmission electron microscopy (TEM) images of the $40 \% \mathrm{Ni} / \mathrm{Al}_{2} \mathrm{O}_{3}$ catalyst and the used $40 \%$ $\mathrm{Ni} / \mathrm{Al}_{2} \mathrm{O}_{3}$ catalyst are shown in Figure 2. As shown in Figure 2a,b, the nickel particles (black spots) were well dispersed on the $\mathrm{Al}_{2} \mathrm{O}_{3}$ support, and the average size of the particles was $12.5 \mathrm{~nm}$, which is smaller than the size of $19.3 \mathrm{~nm}$ determined from the XRD analysis. This result was reasonable because the crystalline size obtained from XRD was the average size for all the nickel particles, whereas that obtained from TEM only represented the size of some parts of the catalyst. As shown in Figure $2 \mathrm{c}, \mathrm{d}$, the average particle size of the used $40 \% \mathrm{Ni} / \mathrm{Al}_{2} \mathrm{O}_{3}$ catalyst was $11.7 \mathrm{~nm}$, which was not significantly different from that of the fresh $40 \% \mathrm{Ni} / \mathrm{Al}_{2} \mathrm{O}_{3}$ catalyst. This result indicates that no catalyst agglomeration occurred after recycling of the catalyst. 


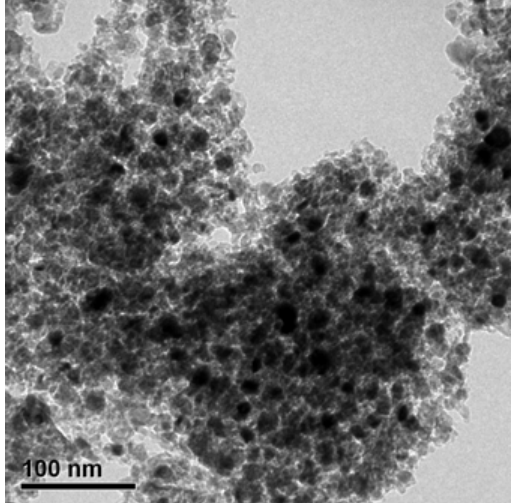

(a)

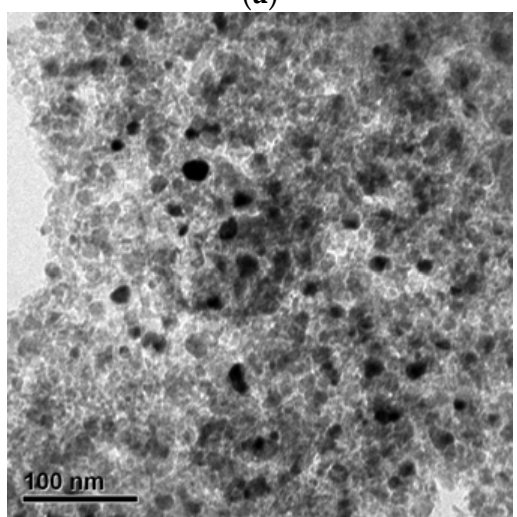

(c)

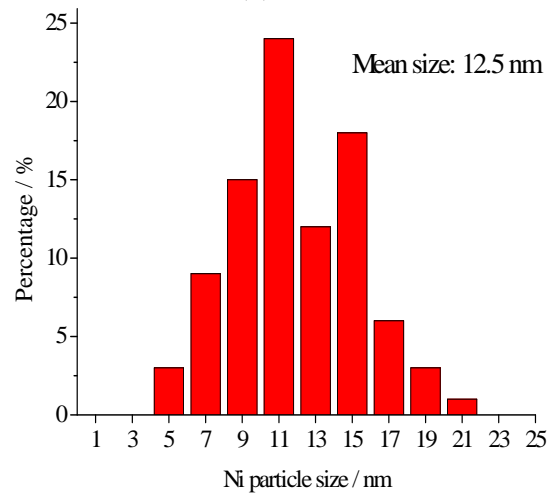

(e)

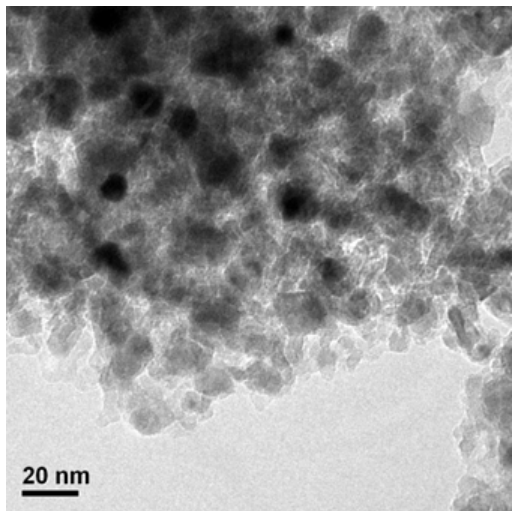

(b)

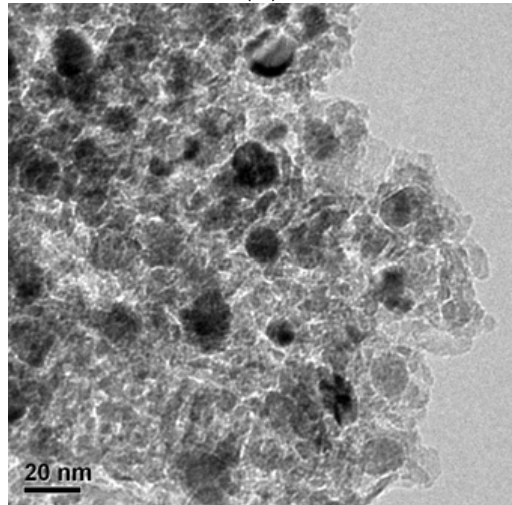

(d)

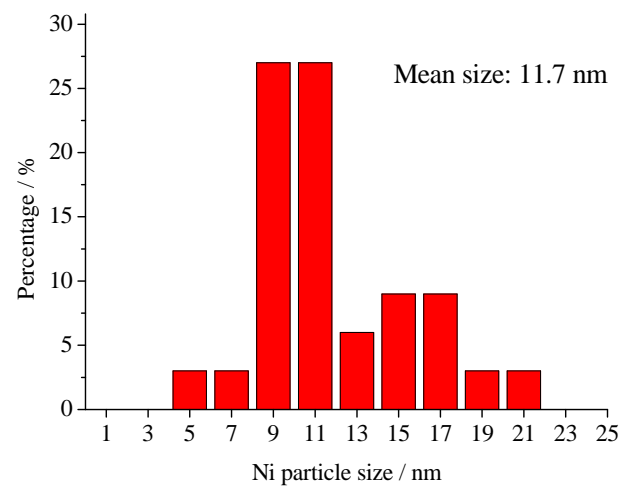

$(\mathbf{f})$

Figure 2. Transmission electron microscopy (TEM) images of fresh $40 \% \mathrm{Ni} / \mathrm{Al}_{2} \mathrm{O}_{3}(\mathbf{a}, \mathbf{b})$ and used $40 \%$ $\mathrm{Ni} / \mathrm{Al}_{2} \mathrm{O}_{3}(\mathbf{c}, \mathbf{d})$, and the particle size distribution of fresh $40 \% \mathrm{Ni} / \mathrm{Al}_{2} \mathrm{O}_{3}(\mathbf{e})$ and used $40 \% \mathrm{Ni} / \mathrm{Al}_{2} \mathrm{O}_{3}(\mathbf{f})$.

\subsection{Catalytic Activity and Stability}

The activities of the synthesized catalysts for the hydrogenation of LA were evaluated in dioxane and water as solvents (Table 2). The reaction temperature was $180^{\circ} \mathrm{C}$ in dioxane and $200{ }^{\circ} \mathrm{C}$ in water, and the hydrogen pressure was maintained constant at $3 \mathrm{MPa}$. For $10 \% \mathrm{Ni} / \mathrm{Al}_{2} \mathrm{O}_{3}$, a $\mathrm{LA}$ conversion of $28.8 \%$ and GVL selectivity of $92.2 \%$ were achieved within $3 \mathrm{~h}$ in water, compared to a conversion of $68.6 \%$ and selectivity of $96.5 \%$ within $2 \mathrm{~h}$ in dioxane. For the other $\mathrm{Ni} / \mathrm{Al}_{2} \mathrm{O}_{3}$ catalysts, higher conversions and selectivities were always achieved with shorter reaction times and lower temperatures in dioxane rather than water as the solvent. Hence, dioxane was favorable for the hydrogenation of LA over $\mathrm{Ni} / \mathrm{Al}_{2} \mathrm{O}_{3}$ catalysts. According to the similarity principle [30], the solubility of hydrogen in dioxane should be higher than that in water. However, the literature reports that there are no significant 
differences between the solubilities of hydrogen in water and dioxane [31,32]. It has been reported that the properties of some types of catalysts change significantly in the presence of water. Holmen et al. [33] reported that both $\mathrm{Co} / \mathrm{Al}_{2} \mathrm{O}_{3}$ and $\mathrm{Co} / \mathrm{Re} / \mathrm{Al}_{2} \mathrm{O}_{3}$ exhibited deactivation when exposed to water vapor during the Fischer-Tropsch synthesis. In our work, $\mathrm{Ni} / \mathrm{Al}_{2} \mathrm{O}_{3}$ might be deactivated in aqueous solution following the deactivation mechanisms of $\mathrm{Co} / \mathrm{Al}_{2} \mathrm{O}_{3}$ and $\mathrm{Co} / \mathrm{Re} / \mathrm{Al}_{2} \mathrm{O}_{3}$ in Holmen's work, which may contribute to the better performance for the hydrogenation of levulinic acid in dioxane than in water.

Table 2. Levulinic acid (LA) conversion, $\gamma$-valerolactone (GVL) yield, and selectivity in dioxane and water over $\mathrm{Ni} / \mathrm{Al}_{2} \mathrm{O}_{3}$ catalysts (LA loading $=1 \mathrm{~g}$, catalyst loading $=0.1 \mathrm{~g}$ ).

\begin{tabular}{cccccccc}
\hline Catalyst & Solvent & $\mathbf{T} /{ }^{\circ} \mathbf{C}$ & $\mathbf{H}_{\mathbf{2}} \mathbf{P} / \mathbf{M P a}$ & Time/h & Conversion/\% & Yield/\% & Selectivity/\% \\
\hline $10 \% \mathrm{Ni} / \mathrm{Al}_{2} \mathrm{O}_{3}$ & water & 200 & 3 & 3 & 28.8 & 26.5 & 92.2 \\
$20 \% \mathrm{Ni} / \mathrm{Al}_{2} \mathrm{O}_{3}$ & water & 200 & 3 & 3 & 94.0 & 88.0 & 93.6 \\
$30 \% \mathrm{Ni} / \mathrm{Al}_{2} \mathrm{O}_{3}$ & water & 200 & 3 & 3 & 96.2 & 86.9 & 90.3 \\
$40 \% \mathrm{Ni} / \mathrm{Al}_{2} \mathrm{O}_{3}$ & water & 200 & 3 & 3 & 98.2 & 93.4 & 95.1 \\
$10 \% \mathrm{Ni} / \mathrm{Al}_{2} \mathrm{O}_{3}$ & dioxane & 180 & 3 & 2 & 68.6 & 66.2 & 96.5 \\
$20 \% \mathrm{Ni} / \mathrm{Al}_{2} \mathrm{O}_{3}$ & dioxane & 180 & 3 & 2 & 96.0 & 94.8 & 98.8 \\
$30 \% \mathrm{Ni} / \mathrm{Al}_{2} \mathrm{O}_{3}$ & dioxane & 180 & 3 & 2 & 100.0 & 98.3 & 98.3 \\
$40 \% \mathrm{Ni} / \mathrm{Al}_{2} \mathrm{O}_{3}$ & dioxane & 180 & 3 & 2 & 100.0 & 99.2 & 99.2 \\
$10 \% \mathrm{Ni} / \mathrm{Al}_{2} \mathrm{O}_{3}$ & dioxane & 180 & 3 & 1 & 40.7 & 39.7 & 97.5 \\
$20 \% \mathrm{Ni} / \mathrm{Al}_{2} \mathrm{O}_{3}$ & dioxane & 180 & 3 & 1 & 57.3 & 55.2 & 96.3 \\
$30 \% \mathrm{Ni} / \mathrm{Al}_{2} \mathrm{O}_{3}$ & dioxane & 180 & 3 & 1 & 77.2 & 74.8 & 96.9 \\
$40 \% \mathrm{Ni} / \mathrm{Al}_{2} \mathrm{O}_{3}$ & dioxane & 180 & 3 & 1 & 82.2 & 80.7 & 98.2 \\
\hline
\end{tabular}

To investigate the effect of nickel loading on the catalytic activities of the $\mathrm{Ni} / \mathrm{Al}_{2} \mathrm{O}_{3}$ catalysts, $\mathrm{LA}$ conversion was performed at $180{ }^{\circ} \mathrm{C}$ for $1 \mathrm{~h}$, and the results are presented in Table 2 . The activity of each catalyst with different nickel loadings for LA conversion was also calculated and followed the order of $40.3 \mathrm{~g}_{\mathrm{LA}} \cdot \mathrm{g}_{\text {catalyst }}{ }^{-1} \cdot \mathrm{h}^{-1}\left(10 \% \mathrm{Ni} / \mathrm{Al}_{2} \mathrm{O}_{3}\right)>28.7 \mathrm{~g}_{\mathrm{LA}} \cdot \mathrm{kg}_{\text {catalyst }}{ }^{-1} \cdot \mathrm{h}^{-1}\left(20 \% \mathrm{Ni} / \mathrm{Al}_{2} \mathrm{O}_{3}\right)$ $>25.7 \mathrm{~g}_{\mathrm{LA}} \cdot \mathrm{g}_{\text {catalyst }}{ }^{-1} \cdot \mathrm{h}^{-1}\left(30 \% \mathrm{Ni} / \mathrm{Al}_{2} \mathrm{O}_{3}\right)>22.1 \mathrm{~g}_{\mathrm{LA}} \cdot \mathrm{g}_{\text {catalyst }}{ }^{-1} \cdot \mathrm{h}^{-1}\left(40 \% \mathrm{Ni} / \mathrm{Al}_{2} \mathrm{O}_{3}\right)$. The $40 \%$ $\mathrm{Ni} / \mathrm{Al}_{2} \mathrm{O}_{3}$ catalyst has the lowest activity, which could also be explained by this catalyst possessing the smallest surface area and largest average crystalline size of metallic nickel, as shown in Table 1. The nickel loading played a critical role in the catalytic activity for the hydrogenation reaction of LA to form GVL.

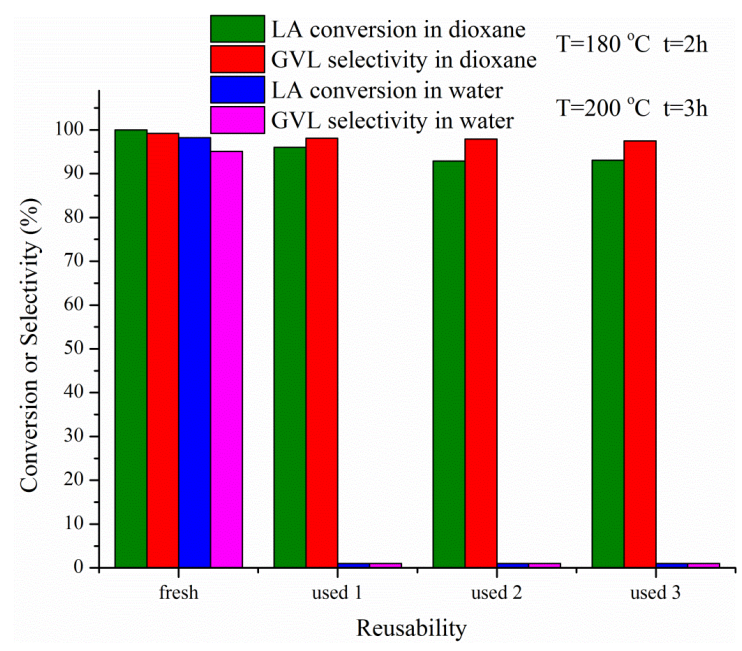

Figure 3. Reusability of the $40 \% \mathrm{Ni} / \mathrm{Al}_{2} \mathrm{O}_{3}$ catalyst in dioxane and water. Dioxane $(40 \mathrm{~mL})$ as the solvent: reaction temperature $=180^{\circ} \mathrm{C}, \mathrm{H}_{2}$ pressure $=3 \mathrm{MPa}$, reaction time $=2 \mathrm{~h}$, LA loading $=1 \mathrm{~g}$, and catalyst loading $=0.1 \mathrm{~g}$; Water as the solvent: reaction temperature $=200{ }^{\circ} \mathrm{C}, \mathrm{H}_{2}$ pressure $=3 \mathrm{MPa}$, reaction time $=3 \mathrm{~h}$, LA loading $=1 \mathrm{~g}$, and catalyst loading $=0.1 \mathrm{~g}$. 
The reusability of the $40 \% \mathrm{Ni} / \mathrm{Al}_{2} \mathrm{O}_{3}$ catalyst was tested, as shown in Figure 3 . The used catalyst was recycled after the hydrogenation reaction by washing with water in an ultrasonic cleaner and drying in a vacuum oven at $60{ }^{\circ} \mathrm{C}$ without hydrogen reduction. The catalyst retained very similar activity for the hydrogenation of LA even after it was used four times in dioxane. In comparison, the catalyst lost activity for the hydrogenation of LA in water after it was used once, indicating that dioxane was favorable for the stability of the catalyst. The characterization results of the used $40 \%$ $\mathrm{Ni} / \mathrm{Al}_{2} \mathrm{O}_{3}$ catalyst are shown in Table 1 and in Figures 1 and 2. The pore volume and pore size of the used $40 \% \mathrm{Ni} / \mathrm{Al}_{2} \mathrm{O}_{3}$ catalyst were smaller than those of the fresh $40 \% \mathrm{Ni} / \mathrm{Al}_{2} \mathrm{O}_{3}$ catalyst, whereas the surface areas of the two catalysts were almost identical. Strong diffraction peaks corresponding to the $\mathrm{NiO}$ phase appeared at $37.2^{\circ}, 43.2^{\circ}$, and $62.8^{\circ}$ in the used $40 \% \mathrm{Ni} / \mathrm{Al}_{2} \mathrm{O}_{3}$ catalyst, which indicates that the catalyst was oxidized to a certain extent. The slight decrease in LA conversion over the used catalyst compared to that over the fresh catalyst might have been caused by slight oxidation of the catalyst. The average crystalline size of metallic $\mathrm{Ni}$ in the $40 \% \mathrm{Ni} / \mathrm{Al}_{2} \mathrm{O}_{3}$ catalyst remained almost unchanged even after it was used four times. The TEM images of the used $40 \% \mathrm{Ni} / \mathrm{Al}_{2} \mathrm{O}_{3}$ catalyst are shown in Figure $2 \mathrm{c}$,d. Metallic nickel was still well dispersed on the $\mathrm{Al}_{2} \mathrm{O}_{3}$ support, and its size was in the range of 10 to $20 \mathrm{~nm}$, which contributed to the stability of the catalyst.

\subsection{Effects of Temperature, Hydrogen Pressure, and Substrate/Catalyst Ratio}

To investigate the effects of the reaction temperature, hydrogen pressure, and substrate-to-catalyst ratio (S/C), a series of hydrogenation experiments were conducted over $40 \% \mathrm{Ni} / \mathrm{Al}_{2} \mathrm{O}_{3}$ as the catalyst. The results are shown in Figure 4. The conversion of LA increased as the reaction temperature increased from 150 to $180^{\circ} \mathrm{C}$, while the GVL selectivity remained high. The hydrogen pressure had a strong effect on the conversion of LA when the hydrogen pressure increased from $1 \mathrm{MPa}$ to $2 \mathrm{MPa}$, whereas the effect was not prominent when the hydrogen pressure increased from $2 \mathrm{MPa}$ to $3 \mathrm{MPa}$. When the hydrogen pressure was greater than $3 \mathrm{MPa}$, it did not affect the reaction. The conversion of LA rapidly decreased when the S/C ratio increased from 10 to 100 , which indicated that the catalyst dosage significantly influenced the hydrogenation reaction.

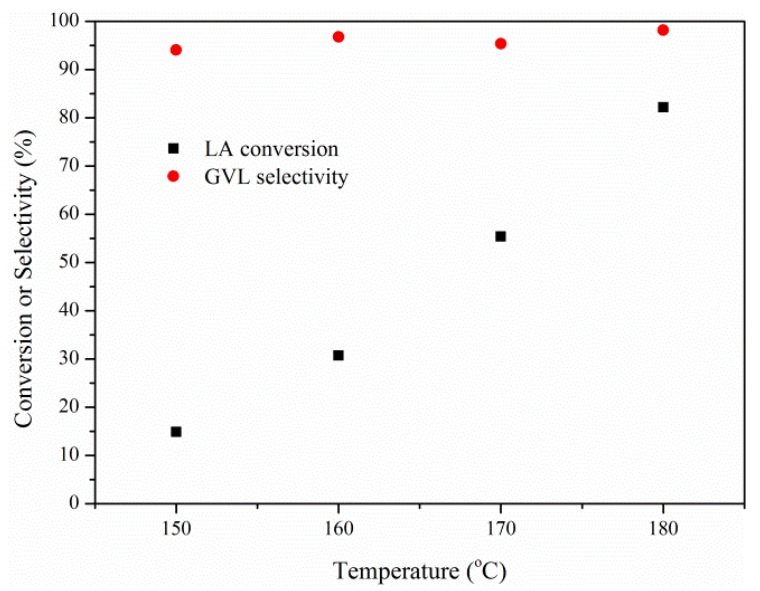

(a)

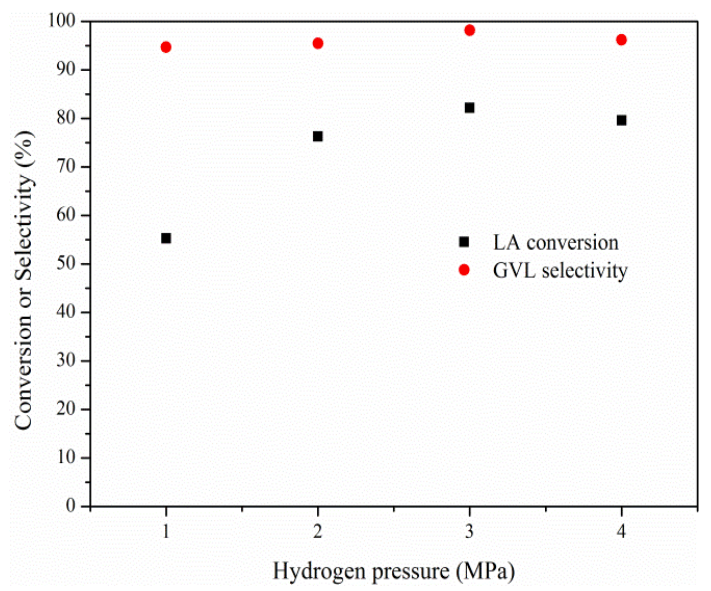

(b)

Figure 4. Cont. 


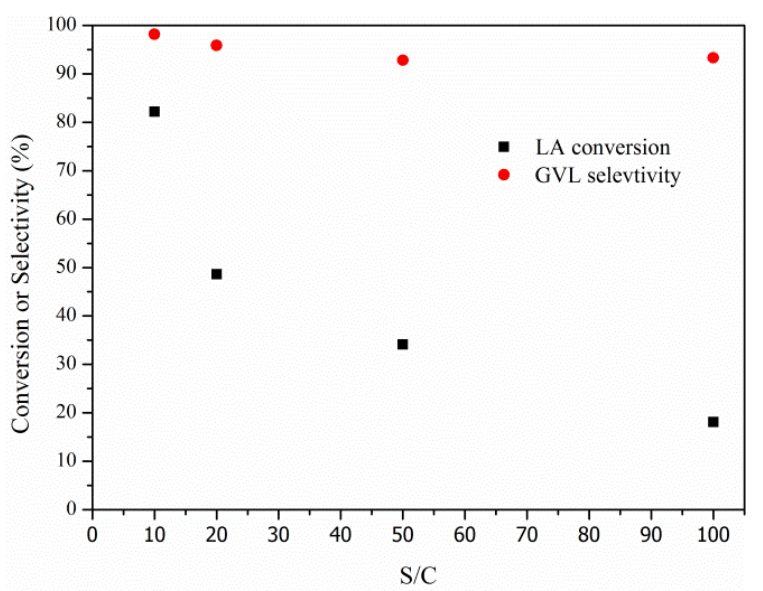

(c)

Figure 4. Effects of reaction temperature, hydrogen pressure, and substrate-to-catalyst ratio (S/C). (a) Effect of temperature: $\mathrm{H}_{2}$ pressure $=3 \mathrm{MPa}$, reaction time $=1 \mathrm{~h}$, LA loading $=1 \mathrm{~g}$, and catalyst loading $=0.1 \mathrm{~g}$; (b) effect of hydrogen pressure: reaction temperature $=180{ }^{\circ} \mathrm{C}$, reaction time $=1 \mathrm{~h}$, LA loading $=1 \mathrm{~g}$, and catalyst loading $=0.1 \mathrm{~g}$; and $(\mathrm{c})$ effect of $\mathrm{S} / \mathrm{C}$ : reaction temperature $=180^{\circ} \mathrm{C}$, $\mathrm{H}_{2}$ pressure $=3 \mathrm{MPa}$, reaction time $=1 \mathrm{~h}$, and LA loading $=1 \mathrm{~g}$.

\section{Experimental Section}

\subsection{Materials}

Nickel nitrate hexahydrate (98\%) and aluminum nitrate hydrate $(99 \%)$ were purchased from the Aladdin Industrial Corporation, Shanghai, China. Levulinic acid (99\%) was purchased from J \& K, Beijing, China. $\gamma$-Valerolactone (99\%) was purchased from Sigma-Aldrich (Louis, MO, USA). Dioxane (99.5\%) was purchased from the Sinopharm Chemical Reagent Co., Ltd., Shanghai, China. Deionized water was prepared in house.

\subsection{Catalyst Preparation}

Nickel-based catalysts, $\mathrm{Ni} / \mathrm{Al}_{2} \mathrm{O}_{3}$, were prepared using the co-precipitation method. Nickel nitrate hexahydrate $\left(\mathrm{Ni}\left(\mathrm{NO}_{3}\right)_{2} \cdot 6 \mathrm{H}_{2} \mathrm{O}\right)$ and aluminum nitrate hydrate $\left(\mathrm{Al}\left(\mathrm{NO}_{3}\right)_{3} \cdot 9 \mathrm{H}_{2} \mathrm{O}\right)$ were dispersed in $250 \mathrm{~mL}$ of deionized water in desired molar ratios and precipitated with approximately $250 \mathrm{~mL}$ of $0.2 \mathrm{M}$ aqueous potassium carbonate at $30^{\circ} \mathrm{C}$. The precipitate was further aged for approximately $6 \mathrm{~h}$ at $30^{\circ} \mathrm{C}$. Then, the precipitate was collected by filtration and washed three times with deionized water to remove excess potassium salt. The precipitate was then dried in a forced air oven at $110^{\circ} \mathrm{C}$ for $12 \mathrm{~h}$, followed by calcination at $450{ }^{\circ} \mathrm{C}$ for $4 \mathrm{~h}$. Prior to the reaction, the calcined catalyst was subjected to a reduction reaction using hydrogen in a tube furnace (flow rate of $100 \mathrm{~mL} / \mathrm{min}$ ) at $650{ }^{\circ} \mathrm{C}$ for $3 \mathrm{~h}$. The used catalyst was recycled after the hydrogenation reaction by washing with water in an ultrasonic cleaner and drying for $12 \mathrm{~h}$ in a vacuum oven at $60^{\circ} \mathrm{C}$ without hydrogen reduction.

\subsection{Catalyst Characterization}

Nitrogen physisorption measurements: Surface areas and pore size distributions were measured using nitrogen as a sorbate gas at $77 \mathrm{~K}$ in a static volumetric apparatus (Micromeritics ASAP2020, Norcross, GA, USA). Prior to the measurements, the samples were degassed at $300{ }^{\circ} \mathrm{C}$ for $16 \mathrm{~h}$. The specific surface areas were calculated using the Brunauer-Emmett-Teller (BET) equation, and the pore sizes and pore volumes were calculated following the method of Barret-Joyner-Halenda $(\mathrm{BJH})$ according to an implemented software routine using the Halsey thickness equation for relating the thickness of the adsorbed layer to the relative pressure. All calculations were based on the adsorption model. 
X-ray diffraction (XRD): X-ray diffraction measurements were performed to identify the metal phases in the synthesized samples and for calculating the crystal sizes using the Scherrer equation. XRD patterns were recorded on a PANalytical Empyrean 200,895, using Ni-filtered $\mathrm{Cu} \mathrm{K} \alpha$ radiation $(\lambda=0.154 \mathrm{~nm})$ as the $X$-ray source (current intensity, $30 \mathrm{~mA}$; voltage, $40 \mathrm{kV})$ and an $X^{\prime}$ Celerator detector. The samples were scanned in the $2 \theta$ range of $20^{\circ}$ to $80^{\circ}$.

Transmission electron microscopy (TEM): The particle sizes and morphologies were investigated using transmission electron microscopy (JEM-2010). A small amount of solid sample was sonicated in acetone for $1 \mathrm{~min}$. Then, a drop of the prepared suspension was deposited onto a $\mathrm{Cu}$ grid coated with a layer of carbon. The grid was dried at room temperature prior to analysis. An electron gun operating at an accelerating voltage of $200 \mathrm{kV}$ was used for the collection of all images.

Thermogravimetric analysis (TGA): The TGA curves were obtained using a thermogravimetric analyzer (TA-Q500). The temperature was scanned from 40 to $850{ }^{\circ} \mathrm{C}$ under a $\mathrm{N}_{2}$ atmosphere with a scan rate of $20^{\circ} \mathrm{C} / \mathrm{min}$.

\subsection{Experimental Procedure}

The hydrogenation of LA was performed in a $100 \mathrm{~mL}$ batch reactor at a stirring speed of $1000 \mathrm{rpm}$. The typical reaction conditions were as follows: a temperature of $180^{\circ} \mathrm{C}$, a hydrogen pressure of $3 \mathrm{MPa}$ (initially, the $100 \mathrm{~mL}$ batch reactor is filled with $3 \mathrm{MPa}$ hydrogen and the hydrogen is released; then, the previous operation is repeated 3 times; and finally, the $100 \mathrm{~mL}$ batch reactor is filled with $3 \mathrm{MPa}$ hydrogen), a dioxane volume of $40 \mathrm{~mL}$, an LA loading of $1 \mathrm{~g}$, and a catalyst loading of $0.1 \mathrm{~g}$. After the reaction, the reaction mixture was filtered, washed, and diluted with deionized water to approximately $250 \mathrm{~mL}$. The compositions of the diluted samples were quantitatively determined using an HPLC (Agilent 1100, Santa Clara, CA, USA) equipped with a refractive index detector. A $20 \mu \mathrm{L}$ sample was loaded into a Phenomenex Gemini $5 \mu \mathrm{m} \mathrm{C18} \mathrm{110A} \mathrm{column}(250 \times 4.60 \mathrm{~mm}, 5 \mathrm{micron})$ and eluted with a mixture (0.1 $\mathrm{mM}$ hydrochloric acid: acetonitrile $=99: 1)$ at a flow rate of $0.6 \mathrm{~mL} / \mathrm{min}$. The column was maintained at $35^{\circ} \mathrm{C}$, and the calibration was performed using commercially available standards.

\section{Conclusions}

Four nickel catalysts supported on aluminum oxide with different nickel loadings were prepared for the hydrogenation of LA to produce GVL using the co-precipitation method. The nickel particles were well dispersed on $\mathrm{Al}_{2} \mathrm{O}_{3}$, and the surface area, pore volume, and pore size decreased as the nickel loading increased. The synthesized $\mathrm{Ni} / \mathrm{Al}_{2} \mathrm{O}_{3}$ catalysts exhibited excellent catalytic activity and stability in dioxane. An LA conversion of $100 \%$ and a GVL yield of $99.2 \%$ were achieved at $180{ }^{\circ} \mathrm{C}$ after $2 \mathrm{~h}$, and the catalyst retained excellent activity even after it was used four times in dioxane. Furthermore, the catalytic activity in dioxane was superior to that in water. The catalyst suffered a certain degree of oxidation during the hydrogenation process, as shown in Figure 1. The conversion of LA increased as the nickel loading increased. A high temperature, high hydrogen pressure, and small S/C ratio were favorable for obtaining a high LA conversion.

Acknowledgments: This work was supported by the National Natural Science Foundation of China (No. 21306165, 21436007), the Zhejiang Provincial Natural Science Foundation of China (No. LQ13B060001), and the Specialized Research Fund for the Doctoral Program of Higher Education of China (No. 20130101120110).

Author Contributions: Xiuyang Lu suggested and supervised the work. Jie Fu wrote the main manuscript with input from all authors. Dong Sheng performed all of the experiments and prepared all the figures and tables. All authors reviewed the manuscript.

Conflicts of Interest: The authors declare no conflicts of interest.

\section{References}

1. Huber, G.W.; Iborra, S.; Corma, A. Synthesis of transportation fuels from biomass: Chemistry catalysts and engineering. Chem. Rev. 2006, 106, 4044-4098. [CrossRef] [PubMed] 
2. Serrano-Ruiz, J.C.; West, R.M.; Dumesic, J.A. Catalytic conversion of renewable biomass resources to fuels and chemicals. Annu. Rev. Chem. Biomol. Eng. 2010, 1, 79-100. [CrossRef] [PubMed]

3. Ragauskas, A.J.; Williams, C.K.; Davison, B.H.; Britovsek, G.; Cairney, J.; Eckert, C.A.; Frederick, W.J.; Hallett, J.P.; Leak, D.J.; Liotta, C.L.; et al. The path forward for biofuels and biomaterials. Science 2006, 311, 484-489. [CrossRef] [PubMed]

4. Jing, Q.; Lü, X. Kinetics of non-catalyzed decomposition of glucose in high-temperature liquid Water. Chin. J. Chem. Eng. 2008, 16, 890-894. [CrossRef]

5. Yang, F.; Fu, J.; Mo, J.; Lu, X. Synergy of Lewis and Brønsted acids on catalytic hydrothermal decomposition of hexose to levulinic acid. Energy Fuels 2013, 27, 6973-6978. [CrossRef]

6. Bui, L.; Luo, H.; Gunther, W.R.; Román-Leshkov, Y. Domino reaction catalyzed by zeolites with Bronsted and Lewis acid sites for the production of gamma-valerolactone from furfural. Angew. Chem. Int. Ed. 2013, 52, 8022-8025. [CrossRef] [PubMed]

7. Horváth, I.T.; Mehdi, H.; Fábos, V.; Boda, L.; Mika, L.T. $\gamma$-Valerolactone-A sustainable liquid for energy and carbon-based chemicals. Green Chem. 2008, 10, 238-242. [CrossRef]

8. Bozell, J.J. Connecting biomass and petroleum processing with a chemical bridge. Science 2010, 329, $522-523$. [CrossRef] [PubMed]

9. Bond, J.Q.; Alonso, D.M.; Wang, D.; West, R.M.; Dumesic, J.A. Integrated catalytic conversion of $\gamma$-valerolactone to liquid alkenes for transportation fuels. Science 2010, 327, 1110-1114. [CrossRef] [PubMed]

10. Pritchard, J.; Filonenko, G.A.; van Putten, R.; Hensen, E.J.; Pidko, E.A. Heterogeneous and homogeneous catalysis for the hydrogenation of carboxylic acid derivatives: History, advances and future directions. Chem. Soc. Rev. 2015, 44, 3808-3833. [CrossRef] [PubMed]

11. Liguori, F.; Moreno-Marrodan, C.; Barbaro, P. Environmentally friendly synthesis of $\gamma$-valerolactone by direct catalytic conversion of renewable sources. ACS Catal. 2015, 5, 1882-1894. [CrossRef]

12. Upare, P.P.; Lee, J.; Hwang, D.W.; Halligudi, S.B.; Hwang, Y.K.; Chang, J. Selective hydrogenation of levulinic acid to $\gamma$-valerolactone over carbon-supported noble metal catalysts. J. Ind. Eng. Chem. 2011, 17, 287-292. [CrossRef]

13. Manzer, L.E. Catalytic synthesis of $\alpha$-methylene- $\gamma$-valerolactone: A biomass-derived acrylic monomer. Appl. Catal. A 2004, 272, 249-256. [CrossRef]

14. Yan, Z.; Lin, L.; Liu, S. Synthesis of gamma-valerolactone by hydrogenation of biomass-derived levulinic acid over RU/C catalyst. Energy Fuels 2009, 23, 3853-3858. [CrossRef]

15. Al-Shaal, M.G.; Wright, W.R.H.; Palkovits, R. Exploring the ruthenium catalysed synthesis of $\gamma$-valerolactone in alcohols and utilisation of mild solvent-free reaction conditions. Green Chem. 2012, 14, 1260-1263. [CrossRef]

16. Galletti, A.M.R.; Antonetti, C.; De Luise, V.; Martinelli, M. A sustainable process for the production of $\gamma$-valerolactone by hydrogenation of biomass-derived levulinic acid. Green Chem. 2012, 14, 688-694. [CrossRef]

17. Ortiz-Cervantes, C.; García, J.J. Hydrogenation of levulinic acid to $\gamma$-valerolactone using ruthenium nanoparticles. Inorg. Chim. Acta 2013, 397, 124-128. [CrossRef]

18. Du, X.; Liu, Y.; Wang, J.; Cao, Y.; Fan, K. Catalytic conversion of biomass-derived levulinic acid into $\gamma$-valerolactone using iridium nanoparticles supported on carbon nanotubes. Chin. J. Catal. 2013, 34, 993-1001. [CrossRef]

19. Luo, W.; Sankar, M.; Beale, A.M.; He, Q.; Kiely, C.J.; Bruijnincx, P.C.A.; Weckhuysen, B.M. High performing and stable supported nano-alloys for the catalytic hydrogenation of levulinic acid to $\gamma$-valerolactone. Nat. Commun. 2015, 6. [CrossRef] [PubMed]

20. Hengne, A.M.; Rode, C.V. Cu-ZrO $\mathrm{rO}_{2}$ nanocomposite catalyst for selective hydrogenation of levulinic acid and its ester to $\gamma$-valerolactone. Green Chem. 2012, 14, 1064-1072. [CrossRef]

21. Yuan, J.; Li, S.; Yu, L.; Liu, Y.; Cao, Y.; He, H.; Fan, K. Copper-based catalysts for the efficient conversion of carbohydrate biomass into $\gamma$-valerolactone in the absence of externally added hydrogen. Energy Environ. Sci. 2013, 6, 3308-3313. [CrossRef]

22. Upare, P.P.; Lee, J.; Hwang, Y.K.; Hwang, D.W.; Lee, J.; Halligudi, S.B.; Hwang, J.; Chang, J. Direct hydrocyclization of biomass-derived levulinic acid to 2-methyltetrahydrofuran over nanocomposite copper/silica catalysts. ChemSusChem 2011, 4, 1749-1752. [CrossRef] [PubMed] 
23. Yan, K.; Chen, A. Efficient hydrogenation of biomass-derived furfural and levulinic acid on the facilely synthesized noble-metal-free Cu-Cr catalyst. Energy 2013, 58, 357-363. [CrossRef]

24. Yan, K.; Chen, A. Selective hydrogenation of furfural and levulinic acid to biofuels on the ecofriendly Cu-Fe catalyst. Fuel 2014, 115, 101-108. [CrossRef]

25. Obregón, I.; Corro, E.; Izquierdo, U.; Requies, J.; Arias, P.L. Levulinic acid hydrogenolysis on $\mathrm{Al}_{2} \mathrm{O}_{3}$-based Ni-Cu bimetallic catalysts. Chin. J. Catal. 2014, 35, 656-662. [CrossRef]

26. Shimizu, K.; Kanno, S.; Kon, K. Hydrogenation of levulinic acid to $\gamma$-valerolactone by Ni and MoO $x$ co-loaded carbon catalysts. Green Chem. 2014, 16, 3899-3903. [CrossRef]

27. Hengst, K.; Schubert, M.; Carvalho, H.W.P.; Lu, C.; Kleist, W.; Grunwaldt, J. Synthesis of $\gamma$-valerolactone by hydrogenation of levulinic acid over supported nickel catalysts. Appl. Catal. A 2015, 502, 18-26. [CrossRef]

28. Mohan, V.; Venkateshwarlu, V.; Pramod, C.V.; Raju, B.D.; Rao, K.S.R. Vapour phase hydrocyclisation of levulinic acid to $\gamma$-valerolactone over supported in catalysts. Catal. Sci. Technol. 2014, 4, 1253-1259. [CrossRef]

29. Lv, J.; Rong, Z.; Wang, Y.; Xiu, J.; Wang, Y.; Qu, J. Highly efficient conversion of biomass-derived levulinic acid into $\gamma$-valerolactone over $\mathrm{Ni} / \mathrm{MgO}$ catalyst. RSC Adv. 2015, 5, 72037-72045. [CrossRef]

30. Wypych, G. Handbook of Solvents; ChemTec. Publishing: New York, NY, USA, 2001; pp. 754-757.

31. Crozier, T.E.; Yamamoto, S. Solubility of hydrogen in water, sea water, and sodium chloride solutions. J. Chem. Eng. Data 1974, 19, 242-244. [CrossRef]

32. Brunner, E. Solubility of hydrogen in 10 organic solvents at $298.15,323.15$, and 373.15 K. J. Chem. Eng. Data 1985, 30, 269-273. [CrossRef]

33. Rothaemel, M.; Hanssen, K.F.; Blekkan, E.A.; Schanke, D.; Holmen, A. The effect of water on cobalt Fischer-Tropsch catalysts studied by steady-state isotopic transient kinetic analysis (SSITKA). Catal. Today 1997, 38, 79-84. [CrossRef]

(C) 2015 by the authors; licensee MDPI, Basel, Switzerland. This article is an open access article distributed under the terms and conditions of the Creative Commons by Attribution (CC-BY) license (http:/ / creativecommons.org/licenses/by/4.0/). 